EPOS, XIV (1998), págs. 277-292

\title{
ARCO, YESO Y CAL: TRES SÍMBOLOS DE LA MUERTE EN LA OBRA DE FEDERICO GARCÍA LORCA
}

JAVIER Salazar RINCón UNED. La Seu D'Urgell

\section{RESUMEN}

Los arcos, especialmente cuando forma parte de un edificio arruinado, como símbolos del paso del tiempo y la destrucción, y también por ser lugares de tránsito, como las puertas y umbrales, entre un más acá y un más allá, tienen para Lorca un significado unívoco relacionado con la muerte y la aniquilación, como puede comprobarse en numerosos pasajes a lo largo de su obra. De todo ello existen conocidos precedentes en la literatura del Barroco y el Romanticismo, y particularmente en la obra de Gustavo Adolfo Bécquer, el precursor inmediato de Lorca en este terreno.

El simbolismo del arco se completa además en la obra del autor con la presencia del yeso y la cal, dos realidades que de inmediato evocan en nuestra memoria las paredes blanqueadas de nichos y cementerios, los paisajes yermos, en que nada crece, $y$, en fin, la palidez, la frialdad y la muerte. 
Egon Huber ', por un lado, y Rafael Martínez Nadal en su estudio sobre $E l$ público $^{2}$, señalaron hace años el significado fúnebre del arco en los escritos de Lorca y su presencia constante como símbolo de muerte en la obra del autor; si bien, en ambos casos, los autores no hicieron más que esbozar un tema de estudio que quisiéramos desarrollar con detalle en las páginas que siguen.

Los arcos a los que alude Lorca en sus escritos, son generalmente arcos rotos, retazos de un edificio ruinoso o un paraje abandonado, restos de la decoración, ya caída, de un cementerio solitario y olvidado, que despiertan en nuestra fantasía sensaciones de abandono, tristeza, acabamiento y muerte, y su origen hay que buscarlo ante todo en la poesía del final del Renacimiento y el Barroco, con precedentes en Castiglione, Sannazaro, Vitale y Garcilaso, que el autor sin duda conocía bien, y en la que los arcos derruidos, antaño signo de gloria, hoy de muerte y destrucción, nos recuerdan, junto a las demás ruinas de la Antigüedad, la huella cruel del tiempo sobre la historia del hombre ${ }^{3}$. Ya en el soneto LXVI de Fernando de Herrera, por ejemplo:

Esta rota i cansada pesadumbre, osada muestra de sobervios pechos, estos quebrados arcos i deshechos, i abierto cerco d'espantosa cumbre

descubren a la ruda muchedumbre su error ciego, i sus términos estrechos; i solo yo en mis grandes males hechos nunca sé abrir los ojos a la lumbre ${ }^{4}$.

En un soneto de Cristóbal de Mesa, incluido en Valle de lágrimas y diversas rimas (Madrid, 1607), se lee:

Teatro, Capitolio, Coliseo, colunas, arcos, mármoles, medallas, estatuas, obeliscos y murallas, do vencieron las obras al deseo;

1 EgON HUBER, Garcia Lorca. Weltbild und metaphorische Darstellung, München, Fink Verlag, 1967, pp. 149-50.

2 Rafael Martínez Nadal, El Público. Amor y muerte en la obra de Federico García Lorca, México, Joaquín Mortiz, 1974, pp. 101-5.

"Véase BRUCE W. WARDROPPER, «The Poetry of Ruins in the Golden Age», Revista Hispanica Moderna, XXXV, 1969, pp. 295-305; y JOSE MARIA FERRI COLL, Las ciudades cantadas. El tema de las ruinas en la poesía española del Siglo de Oro, Alicante, Universidad de Alicante, 1995.

4 Fernando de Herrera, Poesias, edic. de Vicente García de Diego, Madrid, Espasa-Calpe, Col. Clásicos castellanos, 6" edic., 1970, pp. 141-42. 
templos, carros triunfales, gran trofeo

de reinos, de vitorias, de batallas, colosos, epitafios, antiguallas

de los sepulcros que desiertos veo;

pirámides, pinturas, termas, baños, reliquias y ruïnas de la pompa

del edificio de la antigua Roma.

Si puede tanto el curso de los años, podrá ser que también el tiempo rompa mi mal, pues toda cosa acaba y doma ${ }^{5}$.

También Quevedo trató el tema en varias ocasiones, y concretamente en una silva, en la que, recordando la ruinas de Roma, escribe:

\section{Trofeos y blasones}

que, en arcos, diste a leer a las estrellas, y no sé si a invidiar a las más dellas, ¡oh Roma generosa!, sepultados se ven donde se vieron:

en la corriente ondosa.

Tan envidiosos hados te siguieron, que el Tibre, que fue espejo a su hermosura, los da en sus ondas llanto y sepultura; $\mathrm{y}$ las puertas triunfales, que tanta vanidad alimentaron, hoy ruinas desiguales, (que, o sobraron al tiempo, o perdonaron las guerras) ya caducan, $y$, mortales, amenazan donde antes admiraron ${ }^{6}$.

Y en la famosa «Canción a las ruinas de Itálica», de Rodrigo Caro:

Fabio, si tú no lloras, pon atenta la vista en luengas calles destruidas,

5 En Poesía de la Edad de Oro. 11: Barroco, edic. de Jose Manuel Blecua, Madrid, Castalia, 1987, pp. 126-27.

- FRANCISCO DE QUEVEDO, "Roma antigua y moderna», de Las tres musas castellanas [1670], en Poesia original completa, edic. de Jose Manuel Blecua, Barcelona, Planeta, Clásicos Universales Planeta, 1981, p. 114. 


\begin{abstract}
mira mármoles y arcos destrozados, mira estatuas soberbias, que violenta Némesis derrib6, yacer tendidas, y ya en alto silencio sepultados sus dueños celebrados?
\end{abstract}

El motivo literario de las ruinas y los arcos derruidos, devorados por la hierba, como imagen del paso del tiempo, el desengaño y la muerte, se halla de nuevo presente en las creaciones de la época romántica, tanto en la poesía como en la pintura ${ }^{8}$, y en ellas se inspira Lorca de manera más directa, sobre todo en sus primero escritos, como veremos después. Ramón López Soler, por ejemplo, escribía en El Europeo, a propósito del tema:

Y si de aquí pasas a considerar la debilidad del hombre con la fuerza de la Naturaleza; si atiendes a las plantas silvestres que descuellan sobre los arcos y las torres medio caídas; si contemplas al verde musgo cubriendo las estatuas de los dioses y a la yedra enroscándose en las columnas de granito o por el cuerpo de una esfinge, iqué manantial de consideraciones no ofrecerá este nivelamiento de la Naturaleza a tu imaginación pensadora y entusiasmada! [...]

Pero cuando las ruinas producen en nosotros una emoción verdaderamente sublime es cuando elevándose el astro solitario de la noche sobre ellas las alumbra con luz trémula y cadavérica. Los trozos de columnas, los arcos aislados, por entre los cuales se descubren las estrellas y los vecinos montes; las piedras amontonadas, sin orden, y el pájaro de la noche revolotendo por encima de aquellos escombros, forma una lúgubre armonía con el brillo de la Luna, el murmullo de la fuente y el silencio del desierto ${ }^{9}$.

El Duque de Rivas, en un poema directamente inspirado en el tópico barroco:
No ostentes, Roma ufana, tus famosas ruïnas, triste esqueleto de gigantes glorias.
Si cuidosa examinas tanta reliquia vana

7 En Poesía de la Edad de Oro. II: Barroco, edic. cit., pp. 126-27.

8 Véase Guillermo Dfaz Plaja, Introducción al estudio del Romanticismo español, Madrid, Espasa-Calpe, Col. Austral, 4' edic., 1972, pp. 70-80.

${ }^{9}$ El Europeo, n 7, 1824, pp. 227-28; cit. por Gulllermo DIaZ Plaja, op. cit., pp. 77-78. 
de gimnasios y termas, arcos, templos, verás son desengaños vividores, verás que son ejemplos que el tiempo destructor ha perdonado para ser escarmiento a los mortales ${ }^{10}$.

En las cartas y las leyendas de Bécquer, la pintura de las ruinas, con sus arcos carcomidos y musgosos, se halla presente de manera repetida. Así, en el convento de los Templarios, en Soria:

En la época a que nos referimos, los caballeros de la Orden habían ya abandonado sus históricas fortalezas; pero aún quedaban en pie restos de los anchos torreones de sus muros; aún se veían, como en parte se ven hoy, cubiertos de hiedra y campanillas blancas, los macizos arcos de su claustro, las prolongadas galerías ojivales de sus patios de armas, en las que suspiraba el viento con un gemido, agitando las altas hierbas.

En los huertos y en los jardines, cuyos senderos no hollaban hacía muchos años las plantas de los religiosos, la vegetación, abandonada de si misma, desplegaba todas sus galas, sin temor de que la mano del hombre la mutilase, creyendo embellecerla.

Las plantas trepadoras subían encaramándose por los añosos troncos de los árboles; y las sombrías calles de álamos, cuyas copas se tocaban y se confundían entre sí, se habían cubierto de césped; los cardos silvestres y las ortigas brotaban en medio de los enarenados caminos, y en los trozos de fábrica próximos a desplomarse, el jaramago, flotando al viento como el penacho de una cimera, y las campanillas blancas y azules, balanceándose como en un columpio sobre sus largos y flexibles tallos, pregonaban la victoria de la destrucción y la ruina ".

Al describir los restos de un castillo árabe, junto al río Alhama:

De los muros no quedan más que algunos ruinosos vestigios; las piedras de la atalaya han caído unas sobre otras al foso y lo han cegado por completo; en el patio de armas crecen zarzales y matas de jaramago. Por todas partes adonde se vuelven los ojos no se ven más que

10 Angel SaAvedra, Duque de Rivas, «El tiempo», en Obras completas, edición y prólogo de Jorge Campos, Madrid, Atlas, 1957, 3 vols. (Biblioteca de Autores Españoles, 100-102), vol. I, p. 47.

"Gustavo Adolfo BécQuer, «El rayo de luna», en Obras completas, Madrid, Aguilar, 13" edic., 1981, pp. 162-63. 
arcos rotos, sillares oscuros y carcomidos; aquí un lienzo de barbacana, por entre cuyas hendiduras nace la hiedra; allí un torreón que aún se tiene en pie como por milagro; más allá los postes de argamasa con las anillas de hierro que sostenian el puente colgante ${ }^{12}$.

Y en los restos de la iglesia bizantina en la Cabeza del Moro, junto a Toledo:

En el atrio, que dibujaban algunos pedruscos diseminados por el suelo, crecían zarzales y hierbas parásitas, entre los que yacían, medio ocultos, ya el destrozado capitel de una columna, ya un sillar groseramente esculpido con hojas entrelazadas, endriagos horribles, grotescas e informes figuras humanas. Del templo sólo quedaban en pie los muros laterales y algunos arcos rotos ya y cubiertos de hiedra ${ }^{13}$.

Junto a los influjos más próximos del Modernismo y los autores del 98, la inspiración becqueriana es evidente, sorprendente incluso, en las páginas de Impresiones y paisajes, la primera obra publicada por García Lorca ${ }^{14}$, en la cual abundan las descripciones de capillas, cementerios o iglesias abandonados, con sus arcos derruidos, cubiertos de ortigas, espigas o enredaderas:

Por todas partes ruinas color sangre, arcos convertidos en brazos que quisieran besarse, columnas truncadas cubiertas de amarillo y yedra, cabezas esfumadas entre la tierra húmeda, escudos que se borran entre verdinegruras, cruces mohosas que hablan de muerte...

Leemos en las páginas dedicadas a Baeza (OC, III, 65). Los huertos de las iglesias abandonadas:

Todos ellos son grandes, con las paredes de piedras obscuras por las que trepan rosales de té, madreselvas y enredaderas de yedra... Tienen bancos de capiteles medio enterrados y sombrajes de arcos cubiertos de espigas y amapolas (Ibid., 92).

El viajero, que se detiene emocionado ante unas ruinas:

Contempla las antiguas visiones de fortalezas deshechas y siente un cansancio abrumador. Sobre los arcos rotos, en las puertas que entran a recintos alfombrados con ortigas y capiteles yacentes, en las al-

12 «La cueva de la mora», ibid., p. 234.

13 "La rosa de pasión», ibid., p. 298.

14 Para todas las citas de Federico García Lorca que van a continuación utilizamos sus Obras completas, recopilación, cronología, bibliografía y notas de Arturo del Hoyo, Madrid, Aguilar, edición del cincuentenario, 1986, 3 vols., a las que nos referimos con las siglas $O C$, indicando a continuación el volumen y las páginas. 
tas paredes solitarias, la esencia de mil colores tristes se esparció entre los mantos reales de las yedras (Ibid., 101).

Y en Fresdelval:

Hay arcos elegantísimos que aún se tienen en pie soportando las greñas verdes de las yedras. Hay medallones sin cabeza. Hay rosetones góticos que dejan pasar la luz suavemente. Yerbas y flores salvajes cubren la ruina... En el claustro gótico se extiende una gran humedad verde y gris (Ibld., 103).

El arco, en fin, antes de que el tiempo lo destruya, es emblema de tristeza y muerte en los primeros escritos de García Lorca cuando su imagen no denota ruina y destrucción, sino que evoca más bien el claustro de los conventos, con sus pasajes oscuros y piedras enmudecidas, o la vanidad de los monumentos funerarios, en que los arcos y lápidas son signo de vanidad, y del inútil esfuerzo de los hombres para soslayar la presencia de la muerte. Así, en el interior del Monasterio de Silos, el claustro:

Es achatado, bajo, profundo, solemne, fuerte, emotivo. En sus galerías proporcionadas y maravillosamente tristes está clavada la esencia eurítmica de una edad brutal, tosca y solemnemente expresiva. Los arcos viriles y graves se quieren perder en un fondo de negruras y austeridades profundas (Ibid., 45).

$\mathrm{Y}$ ante un sepulcro en Burgos:

Tenemos en toda la dolorosa historia de la humanidad un afán, un ansia grande de perpetuar vidas, o mejor dicho unas vidas que quieren hablamos eternamente por medio de lápidas y de arcos fúnebres... Un sepulcro es siempre una interrogacion...

En la vanidad de los hombres hay negrura interior que les impide ver el más allá. La vanidad está siempre en presente (Ibid., 61).

Pero junto a los valores que hemos indicado - retazos de un paraje en ruinas, ornamento de túmulo funerario-, que continúan presentes en la obra posterior, el arco, como emblema de la muerte, tiene en la obra de Lorca un significado similar al de las puertas, umbrales y entradas en general: punto de encuentro y de separación entre un más acá y un más allá, entre lo profano y lo sagrado, lo conocido y lo desconocido, la luz y la oscuridad, lo cierto y lo misterioso, $y$, en fin, la vida y la muerte ${ }^{15}$; por lo que el acto de cruzar, entrar a tra-

15 Gaston Bachelard, La poética del espacio, México, FCE, 24 edic., 1983, pp. 250-70; y Jean Chevalier y Alain Gheerbrant, Diccionario de los símbolos, Barcelona, Herder, $2^{4}$ edic., 1988, pp. 855-58 y 1063. 
vés del arco, o simplemente acercarse a él, representa para Lorca un camino sin retorno hacia un reino de tinieblas, según leemos en la conferencia titulada «Juego y teoría del duende», redactada en 1933, y en cuyas últimas líneas el autor se preguntaba:

El duende... ¿Dónde está el duende? Por el arco vacío entra un aire mental que sopla con insistencias sobre las cabezas de los muertos, en busca de nuevos paisajes y acentos ignorados; un aire con color de saliva de niño, de hierba machacada y velo de medusa que anuncia el constante bautizo de las cosas recién creadas (OC, III, 318).

Así, el protagonista de la «Burla de don Pedro a caballo», de Romancero gitano (OC, I, 436-38), cabalga ilusionado «en la busca / del pan y del beso», aunque por caminos misteriosos que lo llevan a la muerte:

$$
\begin{aligned}
& \text { Brillan las azoteas } \\
& \text { y las nubes. Don Pedro } \\
& \text { pasa por arcos rotos. } \\
& \text { Dos mujeres y un viejo } \\
& \text { con velones de plata } \\
& \text { le salen al encuentro. } \\
& \text { Los chopos dicen: No. } \\
& \text { Y el ruiseñor: Veremos. }
\end{aligned}
$$

En el romance «Muerto de amor» (OC, 1, 421-22), del mismo libro, hasta el firmamento oscuro y el arco ceniciento de la luna, simulando un paraje en ruinas, acompañan al muchacho en su agonía:

$$
\begin{aligned}
& \text { Brisas de caña mojada } \\
& \text { y rumor de viejas voces, } \\
& \text { resonaban por el arco } \\
& \text { roto de la medianoche. }
\end{aligned}
$$

Aunque su función sólo sea de tipo decorativo, los arcos también adquieren un cierto valor simb6́lico en la tercera estampa de Mariana Pineda: La heroína, condenada a muerte, se encuentra presa entre paredes blancas, en una ambiente de quieta melancolía:

Convento de Santa María Egipciaca, de Granada. Rasgos árabes. Arcos, cipreses, fuentecillas y arrayanes. Hay unos bancos y unas viejas sillas de cuero. Al levantarse el telón está la escena solitaria. Suenan el órgano y las lejanas voces de las monjas (OC, II, 242). 
Y en la escena última, los arcos adquieren extrañas coloraciones para alumbrar los caminos de una muerte embellecida:

Toda la escena irá adquiriendo, hasta el final, una gran luz extrañísima de crepúsculo granadino. Luz rosa y verde entra por los arcos, y los cipreses se matizan exquisitamente, hasta parecer piedras preciosas. Del techo desciende una suave luz naranja, que se va intensificando hasta el final (Ibíd., 269).

En los poemas del ciclo neoyorquino, el arco representa una amenaza o un camino seguro hacia la muerte. El hablante de «Iglesia abandonada. Balada de la gran guerra» $(O C, \mathrm{I}, 464-65)$, por ejemplo, se lamenta:

Yo tenía un hijo que se llamaba Juan.

Yo tenía un hijo.

Se perdió por los arcos un viernes de todos los muertos.

En el «Paisaje de la multitud que orina», también de Poeta en Nueva York $(O C, \mathrm{I}, 475-76)$ :

No importa que el niño calle cuando le clavan el último alfiler, ni importa la derrota de la brisa en la corola del algodón, porque hay un mundo de la muerte con marineros definitivos que se asomarán a los arcos y os helarán por detrás de los árboles.

El protagonista de «El niño Stanton» (OC, I, 495-96), del mismo libro, se nos presenta asediado por la muerte:

...idiota y bello entre los pequeños animalitos, con tu madre fracturada por los herreros de las aldeas, con un hermano bajo los arcos, otro comido por los hormigueros, y el cáncer sin alambrada latiendo por las habitaciones.

En el poema titulado «Muerte» $(O C, \mathrm{I}, 503)$, tras enumerar los imperceptibles e inquietantes signos que acechan nuestra existencia:

Y la rosa, ¿qué rebaño de luces y alaridos ata en el vivo azúcar de su tronco! Y el azúcar, ¡qué puñalitos sueña en su vigilia! $Y$ los puñales diminutos, ¿qué luna sin establos, qué desnudos, piel eterna y rubor, andan buscando! 
El hablante concluye:

Pero el arco de yeso, ¡qué grande, qué invisible, qué diminuto!, sin esfuerzo.

Y en los últimos versos de la «Oda a Walt Whitman» $(O C, I, 532)$, el protagonista querría despojar la tumba del poeta norteamericano de cualquier signo que recordara su muerte:

Quiero que el aire fuerte de la noche más honda

quite flores y letras del arco donde duermes

y un niño negro anuncie a los blancos del oro

la llegada del reino de la espiga.

$\mathrm{Y}$ en los versos de «Tierra y luna» $(O C, \mathrm{I}, 1052-53)$, perteneciente a este ciclo, el hablante, solidario con los seres débiles, ansiosos de vida, heridos o asesinados, exclama:

Me quedo con el transparente hombrecillo que come los huevos de la golondrina.

Me quedo con el niño desnudo que pisotean los borrachos de Brooklyn, con las criaturas mudas que pasan bajo los arcos.

Con el arroyo de venas ansioso de abrir sus manecitas.

El cuadro segundo de El Público, contemporáneo de los poemas neoyorquinos, gira obsesivamente en torno a las relaciones entre el amor y la muerte, y se desarrolla en una «Ruina romana» $(O C$, II, 611). Julieta, en el cuadro siguiente, al saltar fuera del sepulcro como si resucitara, exclama (Ibíd., 628):

Por favor. No he tropezado con una amiga en todo el tiempo, a pesar de haber cruzado más de tres mil arcos vacíos. Un poco de ayuda, por favor. Un poco de ayuda y un mar de sueño. (Canta.)

Un mar de sueño, un mar de tierra blanca y los arcos vacíos por el cielo.

Mi cola por las naves, por las algas.

Mi cola por el tiempo.

Un mar de tiempo.

Playa de los gusanos leñadores

y delfín de cristal por los cerezos. 
¡Oh puro amianto de final! ¡Oh ruina!

¡Oh soledad sin arco! ¡Mar de sueño!

En el cuadro quinto, protagonizado por un hombre Desnudo que recuerda a Cristo, el escenario está formado por «arcos y escaleras», que, al ser destruido el teatro, y después de que el Hombre $1^{\circ}$ grite «iAgonía!», «aparecen teñidos de una granulada luz azul», el destello de la muerte (Ibíd., 647 y 657). Y en fin, según afirma el Director, el verdadero drama, el único que cabe en el teatro auténtico, es aquel en que el hombre se enfrenta sin máscaras a la esencia de la vida y a la angustia de la muerte:

Es rompiendo todas las puertas el único modo que tiene el drama de justificarse, viendo, por sus propios ojos, que la ley es un muro que se disuelve en la más pequeña gota de sangre. Me repugna el moribundo que dibuja con el dedo una puerta sobre la pared y se duerme tranquilo. El verdadero drama es un circo de arcos donde el aire y la llama y las criaturas entran y salen sin tener un sitio donde descansar (Ibid., 668).

En la sección titulada «Carne», de la Oda al Santísimo Sacramento del Al$\operatorname{tar}(O C, \mathrm{I}, 967-69)$, Cristo trae un mensaje de esperanza para el hombre, que desde el pecado original aguarda la luz de la resurrección sumido en un reino de tinieblas:

Adán es luz y espera bajo el arco podrido las dos niñas de lumbre que agitaban sus sienes.

$\mathrm{Y}$ el arco, en fin, como imagen de la muerte, se contrapone y combina en los versos de Diván de Tamarit con los signos del amor, en un extraño juego dialéctico de atracciones y rechazos. Así, en la «Gacela de la terrible presencia" (OC, I, 574), el cuerpo amado ofrece una doble faz, atrayente y peligrosa, y el protagonista prefiere enfrentarse con la muerte antes que soportar su contemplación:

Puedo ver el duelo de la noche herida luchando enroscada con el mediodía.

Resisto un ocaso de verde veneno y los arcos rotos donde sufre el tiempo.

Pero no ilumines tu limpio desnudo como un negro cactus abierto en los juncos. 
Déjame en un ansia de oscuros planetas, pero no me enseñes tu cintura fresca.

Mientras que en la «Gacela del recuerdo de amor» (OC, I, 579-80), es la memoria del amor pasado lo que el poeta desea para afrontar el momento de su tránsito:

Un muro de malos sueños

me separa de los muertos.

La hierba cubre en silencio

el valle gris de tu cuerpo.

Por el arco del encuentro

la cicuta está creciendo.

Pero deja tu recuerdo, déjalo solo en mi pecho.

El significado fúnebre del arco se completa en la obra de García Lorca con el empleo de un símbolo original al que también hace breve referencia Egon Huber en su estudio ${ }^{16}$ : la cal, o su equivalente, el yeso, los cuales, aunque esporádicamente ayuden a recordar el aspecto típico de los pueblos andaluces ${ }^{17}$, contienen alusiones evidentes al dolor, la sequedad y la muerte en numerosos pasajes, y ya en la conferencia sobre el duende citada, el autor recordaba cómo:

La casulla y la rueda del carro, y la navaja y las barbas pinchosas de los pastores, y la luna pelada, y la mosca, y las alacenas húmedas, y los derribos, y los santos cubiertos de encaje, y la cal, y la línea hiriente de aleros y miradores tienen en España diminutas hierbas de muerte, alusiones y voces perceptibles para un espíritu alerta, que nos llenan la memoria con el aire yerto de nuestro propio tránsito ( $«$ Juego y teoría del duende», $O C$, III, 313).

En efecto, la cal y el yeso evocan en primer lugar las tapias, los arcos y los nichos blanqueados de las iglesias y los cementerios; la cal viva se ha utilizado además como materia antiséptica, para evitar la descomposición de la

is EgON HUber, op. cit., pp. 47-48.

17 Así, en el romance «Muerto de amor», de Romancero gitano, «Fachadas de cal ponían / cuadrada y blanca la noche. / Serafines y gitanos / tocaban acordeones» $(O C, 1,422)$. Y en la Tragicomedia de don Cristóbal, el Joven explica: «Encuentro el pueblo más blanco, mucho más blanco. Cuando lo vi desde la Sierra, me entró la luz por los ojos y me llegó hasta los pies. Los andaluces vamos a pintarnos con cal hasta las carnes" $(O C$, II, 125). 
materia orgánica, y nos obliga a pensar en el oficio del enterrador; el yeso, en fin, con sus cristales lechosos, recubre muchas tierras áridas, típicas de nuestra España interior, y nos recuerda los parajes yermos, en que nada crece; y ambos, cal y yeso, con su palidez sin vida, simbolizan por sí solos lo débil, lo enteco, lo aniquilado y lo muerto. Ya en los capítulos dedicados a Baeza en Impresiones y paisajes, por ejemplo, la cal acentúa la desolación de los palacios en ruinas:

Siempre al recorrer estas calles se descubre algo interesante... un capitel de dibujo caprichoso empotrado en la pared, una reja hecha como para una serenata enamorada, algún palacio destrozado y cubierto de cal... (OC, III, 69).

En «Elegía a María Blanchard», conferencia pronunciada en 1932, al acaecer su muerte, el autor elogia la sequedad sin adornos de la artista con las siguientes palabras:

Lo más español de María Blanchard es esta busca y captura de Cristo, Dios y varón realísimo; no al modo de la fantástica Catalina de Siena, que se llega a casar con el Niño Jesús y en vez de anillos se cambian los corazones, sino de un modo seco, tierra pura y cal viva, sin el menor asomo de ángeles o milagro (OC, III, 304).

Blancura hiriente y hierbas venenosas son la sustancia de la que brota la pena en «El paso de la Siguiriya», del Poema del cante jondo $(O C, \mathrm{I}, 161)$, cuando la copla, de vacilante cadencia:

Va encadenada al temblor de un ritmo que nunca llega; tiene el corazón de plata $y$ un puñal en la diestra.
¿Adonde vas, siguiriya, con un ritmo sin cabeza?
¿Qué luna recogerá
tu dolor de cal y adelfa?

La reposada quietud que envuelve a la protagonista de «La monja gitana» $(O C, \mathrm{I}, 404-5)$, y en la que sus ilusiones amorosas van a quedar silenciadas, más que al patio de un convento, nos recuerda la blancura inmaculada y sin vida de un cementerio encalado: 
Silencio de cal y mirto.

Malvas en las hierbas finas.

La monja borda alhelíes

sobre una tela pajiza.

Y cuando una misteriosa voz anuncia al Amargo, otro personaje de Romancero gitano, su final inapelable ( $\propto$ Romance del emplazado», $O C, 1,423$ 25 ), la cal contribuye con su presencia tenaz a la obra de la muerte:

Ya puedes cortar si gustas

las adelfas de tu patio.

Pinta una cruz en la puerta

y pon tu nombre debajo,

porque cicutas y ortigas

nacerán en tu costado,

y agujas de cal mojada

te morderán los zapatos.

En los versos de Poeta en Nueva York, según vimos, el camino de la muerte se inicia bajo un arco de yeso, invisible y diminuto («Muerte», $O C, \mathrm{I}, 503$ ); y en la ciudad, de oquedades y seres de perfil inerte ( Nocturno del hueco», $O C, \mathrm{I}$, 504-6):

Ruedan los huecos puros, por mí, por ti, en el alba conservando las huellas de las ramas de sangre y algún perfil de yeso tranquilo que dibuja instantáneo dolor de luna apuntillada.

En la «Danza de la muerte» $(O C, 1,469-72)$, cuando el mascarón comienza su terrible danza, los costados de los edificios se transforman en muros de cementerio y prisión:

Desfiladeros de cal aprisionaban un cielo vacío donde sonaban las voces de los que mueren bajo el guano.

En el acto tercero de Así que pasen cinco años, antes de que el Arlequín y el Payaso, entre bromas y veras, despojen a la Muchacha de todas sus ilusiones, el escenario nos sitúa en una ambiente frío, con figuras y sugestiones de muerte:

Bosque. Grandes troncos. En el centro, un teatro rodeado de cortinas barrocas con el telón echado. Una escalerilla une el tabladillo con 
el escenario. Al levantarse el telón cruzan entre los troncos dos figuras vestidas de negro, con las caras blancas de yeso y las manos también blancas (OC, II, 560).

$\mathrm{Y}$ un aspecto similar tiene la Máscara que irrumpe en la misma escena:

...traje 1900 con larga cola amarillo rabioso, pelo de seda amarillo, cayendo como un manto, y máscara blanca de yeso (Ibid., 567).

Los caballos que dialogan con el Director en el primer cuadro de $E l$ público, quisieran verlo destruido por la muerte:

$Y$ tus zapatos estaban cocidos por el sudor, pero sabíamos comprender que la misma relación tenía la luna con las manzanas podridas en la hierba [...] Estás cubierto de vello y comes la cal de los muros que no es tuya $(O C, \mathrm{Il}, 600)$.

En el mismo cuadro, el yeso representa la falsedad sin sangre de un teatro que se niega a aceptar las auténticas verdades, aquellas que atentarían contra los buenos sentimientos del espectador:

Hay personas que vomitan cuando se vuelve un pulpo del revés y otras que se ponen pálidas si oyen pronuncias con la debida intención la palabra cáncer; pero usted sabe que contra esto existe la hojalata, y el yeso, y la adorable mica, y, en último caso, el cartón, que como medios expresivos están al alcance de todas las fortunas (Ibid., 605).

Y en el cuadro tercero, Elena, encarnación de la mujer agresiva, enemiga de la homosexualidad, es capaz de aniquilar por la fuerza las ambigüedades y de «pulir sus manos dentro del fósforo y la cal viva» (Ibíd., 625).

La primera sección del Llanto por Ignacio Sánchez Mejias («La cogida y la muerte», $O C, \mathrm{I}, 551-52)$, se inicia con los preparativos para una tragedia que ya se juzga inminente:

A las cinco de la tarde.

Eran las cinco en punto de la tarde.

Un niño trajo la blanca sábana

a las cinco de la tarde.

Una espuerta de cal ya prevenida

a las cinco de la tarde. 
Lo demás era muerte y sólo muerte a las cinco de la tarde.

En los versos de Diván del Tamarit, el amor se nos ofrece tierno y vivo, como un refugio contra la sequedad y la amargura, y así, en la «Gacela del amor maravilloso» $(O C, \mathrm{I}, 582)$ :

Con todo el yeso

de los malos campos,

eras junco de amor, jazmín mojado.

Con sur y llama

de los malos cielos, eras rumor de nieve por mi pecho.

En cambio en la «Casida del amor imprevisto», del mismo libro (OC, I, 573), el amor se vuelve frío, pálido y estéril, lleno de semillas indecisas que no llegarán a ser, cuando:

Entre yeso y jazmines, tu mirada era un pálido ramo de simientes. Yo busque, para darte, por mi pecho las letras de marfil que dicen siempre,

siempre, siempre: jardín de mi agonía, tu cuerpo fugitivo para siempre, la sangre de tus venas en mi boca, tu boca ya sin luz para mi muerte.

Para acompañarle en el momento de su muerte, el poeta querría una mano, aunque fuese fría y yerta, como «un pálido lirio de cal» («Casida de la mano imposible», $O C, \mathrm{I}, 594)$; y, en fin, cuando el amor desaparece por completo, en la «Gacela del recuerdo de amor» $(O C, \mathrm{I}, 579)$, sólo queda muerte y sequedad:

Me separa de los muertos un muro de malos sueños.

Doy pena de lirio fresco para un corazón de yeso.

Toda la noche, en el huerto mis ojos, como dos perros.

Toda la noche, comiendo los membrillos de veneno. 